\title{
Relationship between Job Attitude and Job Performance of Reception Staff at General Hospital in Seoul
}

\author{
Yeon Suk $\mathrm{Oh}^{1}$, Mi Joon $\mathrm{Lee}^{2}$ and Bum Jeun $\mathrm{Seo}^{3}$ \\ ${ }^{1}$ General Manager, Department of Global Cooperation, SungAe General \\ Hospital \\ ${ }^{2}$ Lecturer, Department of Nursing, Hanyang University \\ ${ }^{3}$ Student, Graduate School of Public Health, Yonsei University \\ 133-791, 222 Wangsimni-Ro, Seongdong-gu, Seoul 133-791, Korea. \\ mijoon63@naver.com \\ *Corresponding Author: Mi Joon Lee
}

\begin{abstract}
This research looked into the impacts of the individual job attitudes of reception window staffs working in general hospitals on their job performance. It was conducted to provide hospitals with effective human resource management and baseline data about hospital management. The subjects of this study were the emotional workers in charge of tasks such as payments, receipts, consultations for first medical examinations, issuance of certificates, procedures for hospitalization and discharges, medical consultations, reception window for the descriptions of examinations, outpatient reception window, industrial accidents and traffic accidents at 15 general hospitals in Seoul. Sampling was done with a total of 350 persons, and 319 copies were analyzed. Through a selfadministered questionnaire survey, a five-point scale was used. This study aims to look into the impacts of the job attitudes of the reception staff on adaptive work performance and the effects of the adaptive work performance on job performance. In the results of the study, it was found that the job attitudes of the reception staff in charge of customer service encounters in hospitals had significant positive impacts on job performance with work performance as a mediating factor. As for the impacts of adaptive work performance on job performance, adaptive response performance and adaptive knowledge performance had impacts on that. As for the impacts of job attitude and work performance on job performance, customized responses, adaptive response performance and adaptive knowledge performance had impacts on that. Therefore, applying a customer-oriented disposition and the element of learning orientation to any future staff at the reception windows in hospitals in the recruitment, education and training of employees will be able to improve job performance.
\end{abstract}

Keywords: Hospital management, Learning orientation, Job Performance, Education

\section{Introduction}

Recently, the environment surrounding medical services has changed rapidly. As the economic growth in Korea advances, medical needs of the people become diversified and competition in medical services is increasingly intensified. Thus, a need for research on the recognition and quality improvement of the changing healthcare environment in the medical profession and academia is increasing. Especially, the hospital is a highly human resource dependent organization, and service quality of the staff is very important for hospital operation [2]. The reception window is the service that customers first encounter when they visit a hospital for the first time. Since the level of the customer satisfaction is determined in a short time when they see the employee who provides the service, the importance of the Moment Of Truth (MOT), at which the customer and the employee make contact, has come to the fore [1]. The effects of skill or knowledge to understand 
the customer's needs on performance were verified by Szymanski[11]. In South Korea, there have been studies of hospital employees' satisfaction with the overall internal service [1], individual-job suitability and individual performance [3] and hospital employees' job satisfaction [4], but there were not enough in-depth studies of its relationship with the hospital reception staff's job performance, reflecting their distinctiveness. Thus, this study attempted to understand the factors affecting job performance of the employees working the reception window. Especially, it is important for the reception window workers at hospitals to figure out and understand the needs of the customers, based on customer-oriented attitudes and appropriate medical knowledge and provide them with proper services, so the learning oriented attitude is also important. Therefore, this study attempted to understand the ultimate impacts of customer-oriented dispositions and the learning oriented attitudes of the staff at the reception windows in hospitals on job performance such as customer satisfaction and customers' re-visits. At this time, work performance was assumed to be a psychological attitude inside the staff appearing externally, and was taken as a mediating factor. The set model and study presented in this study will be used as baseline data for the enhancement of customer satisfaction and the business performance by the placement of the reception window staff for the right place in the future workforce management of the staff at the reception window in hospitals.

\section{Method}

\subsection{Research Design}

This research reviewed preceding research on the job performance of the employees in the service industry. There is the study of Spiro and Weitz who reported that job performance of salespersons differs depending on their approach in the relationship with customers[8]. As a theoretical basis, referring to Yun, Dong-gi, through a factorial analysis, the job attitudes of the staff at the reception window in hospitals were divided into the dimension of customer orientation such as customized responses and efforts to maintain customer relationships and that of learning orientation such as pursuit of-to-date knowledge and business application. In addition, their adaptive work performance was composed of adaptive response performance and adaptive knowledge performance. As a mediating factor to form job performance, adaptive work performance was assumed to be customized to the customers' eye level based on medical knowledge[12].

\subsection{Subjects of Research and Ethical Consideration}

This research selected the persons in charge of payments, receipts, consultations for first medical examination, issuance of certificates, procedures for hospitalization and discharges, medical consultations, reception window for the description of examinations, outpatient reception window, industrial accidents and traffic accidents at 15 general hospitals in Seoul as a population (a total of 350 persons). A survey was conducted with those who understood and agreed with the purpose of the study for 25 days from May 1 through May 25, 2013. Of them, 329 copies (collection ratio: 91.1\%) were selected as the subjects of the final analysis, excluding the 31 copies in which there was a refusal of responses or unreliable responses.

\subsection{Research Tools}

This study defined general characteristics, the customer orientation, learning orientation, adaptive work performance and job performance through a review of preceding studies. Also, a measurement tool was drawn up after a review of two doctors in business administration, referring to the preceding studies. The content validity was verified by 10 heads of the administration department. For measurements, a five-point Likert scale was used, and points were set as follows: (1="Never.", $2="$ Not likely.", $3=$ =" Neutral.", 4=" Likely.", 5=" Very likely."). 


\subsubsection{Validity and Reliability of the Main measurement Variables}

The reception staff at the general hospital analyzed the validity and reliability of the configuration concepts of job attitude, work performance and job performance, etc. The convergent validity of the configuration concepts was verified by a factorial analysis while their reliability was checked by Cronbach's $\alpha$ coefficient. Over 0.4 was applied as the standard for the discretion of significant factors, and Cronbach's $\alpha$ coefficient over 0.6 was applied as the standard for the judgment of the confidence factor. As a result of the reliability of the concepts, Cronbach's a value turned out to be 0.879 , so it was found that the variables used in this study have internal consistencies among the items.

\subsubsection{Customer Orientation}

Generally, when customers purchase products and services, they come into contact with front-line employees who construct a corporate image representing their company, instead of dealing with the entire company. In this sense, Crosby, Evans \& Cowles (1990) states, "The salesperson is the company to customers," which emphasize the role of the front line employees who contact the customers representing the company at the very front line[6]. In this study, the customer orientation was defined as attitudes and behaviors of the hospital reception staff working in the department of customer service encounter, to support patients' uses of a medical institution such as responding to them and their needs. A measurement tool was composed of a total of 11 questions: seven about customized responses and four about efforts to maintain customer relationships. A higher Likert score was interpreted as higher customer orientation. The reliability of this study was Cronbach's alpha, .84 for customized responses and Cronbach's alpha, .79 for efforts to maintain customer relationships.

\subsubsection{Learning Orientation}

Learning orientation means people's tendency to improve their skills in order to complete the task they perform [9]. Also, Szymanski (1988) verified the ability to determine the customers' desire or the impact of knowledge on the performance. He said that salespersons with learning-oriented tendencies attach importance to the process of finding more effective marketing methods [5] and are attracted by challenging situations of sales, so they are not afraid of making mistakes, and they find personal growth through their job and feeling and value of the completion of the job. In this study, the learning orientation was defined as the hospital reception staff's disposition to acquire all the knowledge necessary for reception window work, such as the latest medical policy and knowledge, and skills in customer counseling to improve their own skills. A measurement tool was composed of a total of six questions: four about pursuit of-to-date knowledge and two about business application. A higher Likert score was interpreted as higher learning orientation. The reliability of this study was Cronbach's alpha, .84 for customized responses and Cronbach's alpha, 79 for efforts to maintain customer relationships.

\subsubsection{Adaptive Performance}

Weitz, Sujan and Sujan (1986) suggested an adaptive selling structure. They suggested that adaptive selling is influenced by customer types and knowledge about marketing strategy, as well as motivation for changing the direction of the behavior of salespersons. In this study, the adaptive performance was assumed to have two aspects, the learned knowledge and customer-oriented responses, and defined as changing work behaviors while in interaction or not based on essential information and knowledge about situations. A measurement tool was composed of eight questions: 4 questions of adaptive response performance and 4 questions of adaptive knowledge performance. The higher the Likert 
score, the higher the customer orientation became. The reliability of this study was Cronbach's alpha, .80 for adaptive response performance and Cronbach's alpha, .81 for adaptive knowledge performance.

\subsubsection{Job Performance}

Since there is a strong intangible quality of customer satisfaction in the hospital reception staff's job performance, there are difficulties in the definition and measurement of the concept. For analysis, Yun, Dong-gi (2005) divided job performance into outputoriented, objective and action-oriented, subjective aspects. Output-oriented job performance refers to single tangible results, such as sales, revenue, number of hospital customers and re-visits, etc., and it is convenient to evaluate the job performance of each individual using it. In this study, the hospital reception staff's job performance was defined as the customer satisfaction and revisit degree perceived by them. In other words, it was composed of four questions: 'My job performance is excellent, overall,' 'Customers I meet trust me,' 'My customers are satisfied with my services' and 'Revisit customers tend to come to me again.' The higher the point on the Likert scale, the higher customer orientation became. The reliability of this study was Cronbach's alpha, .88 .

\subsection{Data Analysis}

The data collected in this study were analyzed with SPSS/WIN ver. 20.0, and specific analytical methods are as follows:

First, the frequency and percentage of the general characteristics of the subjects were calculated; Second, as a factorial analysis of general characteristics, t-test and ANOVA were conducted, and a post-analysis was conducted by Scheffe test;

Third, regarding the relevance of each factor among the concepts of job performance, work performance and job attitude, a correlation analysis (Pearson's correlation) was conducted; and Fourth, to understand the relationship between job attitude and job performance, regression analyses were conducted between job attitude and work performance, between work performance and job performance, and on the simultaneous impacts of job attitude and work performance on job performance.

\section{Results}

\subsection{General Characteristics of Subject}

The demographic characteristics of the subjects of the study were as follows: By sex, $22.9 \%$ were males and $77.1 \%$ were females. By age (sectionalized), $40.8 \%$ were under 29 ; $42.0 \%, 30-39$; and $17.2 \%$, over 40 . By marital status, $56.1 \%$ were unmarried and $43.9 \%$, married. By employment status, $81.5 \%$ were in a regular position and $18.5 \%$, in a non-regular position. By educational background, $16.0 \%$ were high school graduates; $48.9 \%$, college graduates; and $35.1 \%$, university graduates or higher. By the period of employment in the current hospital, $40.8 \%$ were less than 36 months, $13.5 \%, 37$ to 60 months; and $45.8 \%$, more than 61 months. By the type of occupation, $18.2 \%$ were in nursing; $63.0 \%$, in administrative position; $18.0 \%$, in medical engineering (others included) (Table 1).

Table 1. General Characteristics of Subject

$(\mathrm{N}=319)$

\begin{tabular}{|c|c|c|c|}
\hline & & Frequency & Percentage (\%) \\
\hline \multirow{2}{*}{ Sex } & Male & 73 & $22.9 \%$ \\
\hline & Female & 246 & $77.1 \%$ \\
\hline Age (sectionalized) & $\begin{array}{l}\text { Under } 29 \\
30-39\end{array}$ & $\begin{array}{l}130 \\
134\end{array}$ & $\begin{array}{l}40.8 \% \\
42.0 \%\end{array}$ \\
\hline
\end{tabular}




\begin{tabular}{llll} 
& Over 40 & 55 & $17.2 \%$ \\
\hline \multirow{2}{*}{ Marital status } & Unmarried & 179 & $56.1 \%$ \\
& Married & 140 & $43.9 \%$ \\
\hline \multirow{2}{*}{ Employment status } & Regular position & 260 & $81.5 \%$ \\
& Non-regular position & 59 & $18.5 \%$ \\
\hline \multirow{2}{*}{ Educational } & High school graduation & 51 & $16.0 \%$ \\
background & College graduation & 156 & $48.9 \%$ \\
& University graduation or higher & 112 & $35.1 \%$ \\
\hline \multirow{2}{*}{ Hospital } & Less than 36 months & 130 & $40.8 \%$ \\
employment period & 37 - 60 months & 43 & $13.5 \%$ \\
& More than 61 months & 146 & $45.8 \%$ \\
\hline \multirow{2}{*}{ Type of occupation } & Nursing & 58 & $18.2 \%$ \\
& Administrative position & 201 & $63.0 \%$ \\
\multirow{2}{*}{ Total } & Medical engineering (others included) & 60 & $18.8 \%$ \\
\hline
\end{tabular}

\subsubsection{Customized Responses by General Characteristics}

As a result of an analysis through one-way ANOVA on whether there is a difference in customized responses by age, there was a statistically significant difference at a confidence level of $99.9 \%(\mathrm{~F}=11.38, \mathrm{p}<.001)$. As a result of an analysis through independent sample t-test on whether there is a difference in customized responses by marital status, there was a statistically significant difference at a confidence level of 99.9\% ( $\mathrm{t}=-3.932, \mathrm{p}<.001)$. As a result of an analysis through one-way ANOVA on whether there is a difference in customized responses by the years of hospital service, there was a statistically significant difference at a confidence level of 99\% ( $\mathrm{F}=5.693$, $\mathrm{p}<.01$ ). As a result of an analysis through one-way ANOVA on whether there is a difference in customized responses by age, customized responses, there was a statistically significant difference at a confidence level of $95 \%$ confidence level $(\mathrm{F}=4.135, \mathrm{p}<.05)$. As a result of an analysis through independent sample t-test and one-way ANOVA on whether there is a difference in customized responses by the remaining items, there was no statistically significant difference at a confidence level of $95 \%(\mathrm{p}>.05)$

\subsubsection{Efforts to Maintain Customer Relationships by General Characteristics}

As a result of an analysis through one-way ANOVA on whether there is a difference in efforts to maintain customer relationships by age, there was a statistically significant difference at a confidence level of $95 \%(\mathrm{~F}=4.032, \mathrm{p}<.05)$. As a result of an analysis through independent sample t-test on whether there is a difference in efforts to maintain customer relationships by marital status, there was a statistically significant difference at a confidence level of $99 \%(\mathrm{t}=-2.933, \mathrm{p}<.01)$. As a result of an analysis through one-way ANOVA on whether there is a difference in efforts to maintain customer relationships by the years of hospital service, there was a statistically significant difference at a confidence level of $99 \%(\mathrm{~F}=5.046, \mathrm{p}<.01)$. As a result of an analysis through one-way ANOVA on whether there is a difference in efforts to maintain customer relationships by the type of occupation, there was a statistically significant difference at a confidence level of $99 \%$ $(\mathrm{F}=6.692, \mathrm{p}<.01)$. As a result of an analysis through independent sample t-test and oneway ANOVA on whether there is a difference in efforts to maintain customer relationships by the remaining items, there was no statistically significant difference at a confidence level of $95 \%$ ( $p>.05)$. 


\subsubsection{Business Application by General Characteristics}

As a result of an analysis through independent sample t-test on whether there is a difference in business application by marital status, there was a statistically significant difference at a confidence level of $95 \%(\mathrm{t}=-2.920, \mathrm{p}<.01)$. As a result of an analysis through independent sample t-test and one-way ANOVA on whether there is a difference in business application by the remaining items, there was no statistically significant difference at a confidence level of $95 \%$ ( $>>05)$.

\subsection{Adaptive Response Performance by General Characteristics}

As a result of an analysis through one-way ANOVA on whether there is a difference in adaptive response performance by age, there was a statistically significant difference at a confidence level of $99.9 \%(\mathrm{~F}=16.592, \mathrm{p}<.001)$. As a result of an analysis through independent sample t-test on whether there is a difference in adaptive response performance by marital status, there was a statistically significant difference at a confidence level of $99.9 \%(\mathrm{t}=-4.463, \mathrm{p}<.001)$. As a result of an analysis through one-way ANOVA on whether there is a difference in adaptive response performance by the years of hospital service, there was a statistically significant difference at a confidence level of 99.9\% $(\mathrm{F}=15.613, \mathrm{p}<.001)$. As a result of an analysis through independent sample t-test and one-way ANOVA on whether there is a difference in adaptive response performance by the remaining items, there was no statistically significant difference at a confidence level of $95 \%(\mathrm{p}>.05)$.

\subsubsection{Business Application by General Characteristics}

As a result of an analysis through one-way ANOVA on whether there is a difference in adaptive knowledge performance by age, there was a statistically significant difference at a confidence level of $99.9 \%(\mathrm{~F}=9.989, \mathrm{p}<.001)$. As a result of an analysis through independent sample t-test on whether there is a difference in adaptive knowledge performance by marital status, there was a statistically significant difference at a confidence level of $99.9 \%$ ( $\mathrm{t}=-4.298, \mathrm{p}<.001)$. As a result of an analysis through one-way ANOVA on whether there is a difference in adaptive knowledge performance by the years of hospital service, there was a statistically significant difference at a confidence level of 99.9\% ( $\mathrm{F}=10.797, \mathrm{p}<.001)$. As a result of an analysis through independent sample t-test and one-way ANOVA on whether there is a difference in adaptive knowledge performance by the remaining items, there was no statistically significant difference at a confidence level of $95 \%$ ( $p>.05$ ).

\subsubsection{Job Performance by General Characteristics}

As a result of an analysis through one-way ANOVA on whether there is a difference in job performance by age, there was a statistically significant difference at a confidence level of $99.9 \%(\mathrm{~F}=12.493, \mathrm{p}<.001)$. As a result of an analysis through independent sample $\mathrm{t}$-test on whether there is a difference in job performance by marital status, there was a statistically significant difference at a confidence level of $99 \%(\mathrm{t}=-2.990, \mathrm{p}<.01)$. As a result of an analysis through independent sample t-test on whether there is a difference in job performance by employment status, there was a statistically significant difference at a confidence level of 95\% ( $\mathrm{t}=0.023, \mathrm{p}<.05)$. As a result of an analysis through one-way ANOVA on whether there is a difference in job performance by the years of hospital service, there was a statistically significant difference at a confidence level of $99.9 \%(\mathrm{~F}=11.325, \mathrm{p}<.001)$. As a result of an analysis through one-way ANOVA on whether there is a difference in job performance by the type of occupation, there was a statistically significant difference at a confidence level of $99 \%(\mathrm{~F}=6.023, \mathrm{p}<.01)$. As a 
result of an analysis through independent sample t-test and one-way ANOVA on whether there is a difference in job performance by the remaining items, there was no statistically significant difference at a confidence level of $95 \%(\mathrm{p}>.05)$.

\section{Conclusion}

This study looks into the effects of customer-oriented and learning-oriented job attitudes of the hospital reception window staff, whose importance has been overlooked, on the hospital's ultimate job performance. The hospital reception window is the first customer service encountered when a customer visits a hospital. Customers recognize the attitude of the staff who they encounter first as the hospital service, which determines the formation of awareness of the hospital's overall service quality. The reception window work in a hospital is not simply that of administrative reception, but it should understand customers' needs and provide information about appropriate services meeting their needs. Thus, this suggests the importance of the placement of experienced personnel that have active business attitudes and can provide differentiated services for customers.

In particular, this study proposes 'customer orientation' and 'learning orientation' as two factors of the hospital reception staff's job attitude. Customer orientation means a service-oriented mindset to pay attention to a customer's needs while learning orientation means an attitude to have proper medical knowledge and counseling skills. Customized service for customers can be achieved when these two factors are prepared as essential factors. In addition, till now, for hospital reception staff, the importance of learning orientation has been overlooked as compared to that of customer orientation, and this study suggests that the acquisition of the latest medical knowledge and learning orientation of medical administrative knowledge is important for the hospital reception staff. Therefore, it is expected that reflecting this in recruitment, selection and training of hospital employees will promote the service quality of the hospital and job performance of its employees.

\section{References}

[1] S. H. Kim, Y. H. Kim and J. M. Kim, "The Effects of Internal Service Quality Factors on Customer Orientation in Small and Medium Hospitals", Korean journal of hospital management, vol. 17, no. 2, (2012), pp. 1-20.

[2] C. T. Kim, S. M. Kang and C. W. Park, "Effects of the Role Conflict, Am-biguity, and Job Satisfaction of the Health Professionals to Their Customer Orientation", Journal of the Korean Society of Radiology, vol. 9, no. 1, (2015), pp. 23-30.

[3] C. W. Lee, "The Mediating Effect of Self-Efficacy in the Relationship between Hospital Employee's Job Placement and Individual Performance", Journal of the Korea Academia-Industrial cooperation Society, vol. 15, no. 1, (2014), pp. 113-121.

[4] J. E. Lim, "The Relationship between Empowerment, Job Satisfaction and Organizational Citizenship Behavior", Korea Journal of Business Administration, vol. 27, no. 7, (2014), pp. 1013-1030.

[5] C. Ames and J. Archer, "Achievement Goals in the classroom: Students' Learning Strategies and Motivation Process", Journal of Educational Psychology, vol. 80, no. 3, (1988), pp. 260-67.

[6] L. A. Crosby, K. R. Evans and D. Cowles, "Relationship quality in services selling: an interpersonal influence perspective", Journal of Marketing, vol. 54, (1990), pp. 68-81.

[7] R. Saxe and B. A. Weitz, "The SOCO Scale: A Measure of the Customer Orientation of Salespeople", Journal of Marketing Research, vol. 19, (1982), pp. 550-562.

[8] R. L. Spiro and B. A. Weitz, "Adaptive Selling: Conceptualization, Measurement, and Nomological Validity", Journal of Marketing Research, vol. 27, (1990), pp. 61-69.

[9] H. Sujan, B. A. Weitz and N. Kumar, "Learning Orientation, working Smart, and Effective Selling", Journal of Marketing, vol. 58, (1994), pp. 39-52.

[10] D. M. Szymanski, "Determinants of Selling Effectiveness: The Importance of Declarative Knowledge to the Personal Selling Concept", Journal of Marketing, vol. 52, (1988), pp. 64-77.

[11] B. A. Weitz, H. Sujan and M. Sujan, "Knowledge, Motivation, and Adaptive Behavior A Framework for Improving Selling Effectiveness", Journal of Marketing, (1986).

[12] Y. Oh, M. Lee and B. Seo, "Education for Job Performance of Receptionists in General Hospital Front Desk", Proc. Advanced Science and Technology Letters, vol. 92, (2015), pp. 119-124. 


\section{Authors}

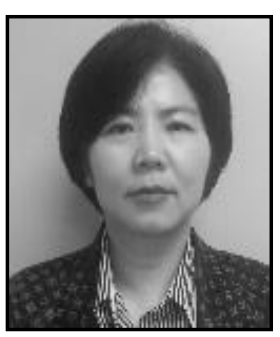

Yeon-Suk Oh, she was born in Korea, on March 18, 1963. She is now a general manager in SungAe General Hospital. She was graduated from Public Health Inje University. Her recent interests focus on patient referral system.

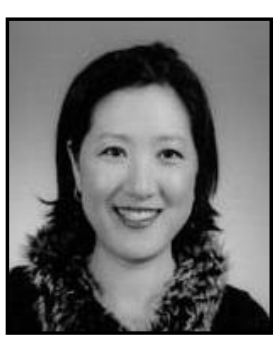

Mi-Joon Lee, she was born in Korea, on October 3, 1963. She is now the Ph.D. student in Nursing of Hanyang University. She is a Lecturer in Department of Nursing, Hanyang University. Her recent interests focus on the healthcare system and bioinformatics.

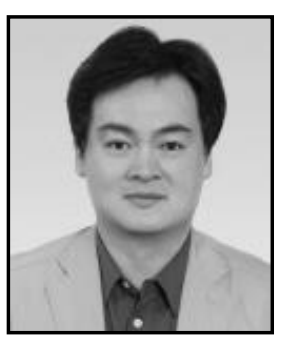

Bum-Jeun Seo, he was born in Korea, on May 20, 1970. He is now the student Graduate School of Public Health Yonsei University. His recent interests focus on u-Healthcare and health care information system. 